\title{
In Vivo Gene Transfer to Dopamine Neurons of Rat Substantia Nigra via the High-Affinity Neurotensin Receptor
}

\author{
Ikuri Alvarez-Maya, ${ }^{1}$ Ivan Navarro-Quiroga, ${ }^{2}$ Marco Antonio Meraz-Ríos, ${ }^{3}$ Jorge Aceves, $^{2}$ \\ and Daniel Martinez-Fong ${ }^{2}$ \\ ${ }^{1}$ Departamento de Biología Celular, Centro de Investigación y de Estudios, Avanzados del Instituto \\ Politécnico Nacional de México, Mexico \\ ${ }^{2}$ Departamento de Fisiología, Biofísica y Neurociencias, \\ ${ }^{3}$ Departamento de Biomedicina Molecular, Centro de Investigación y de Estudios Avanzados del Instituto \\ Politécnico Nacional de México, Mexico \\ Contributed by A. Martinez-Palomo. Accepted November 23, 2000
}

\begin{abstract}
Background: Recently, we synthesized a nonviral gene vector capable of transfecting cell lines taking advantage of neurotensin (NT) internalization. The vector is NT cross-linked with poly-L-lysine, to which a plasmid DNA was bound to form a complex (NT-polyplex). Nigral dopamine neurons are able to internalize NT, thus representing a target for gene transfer via NT-polyplex. This hypothesis was tested here using reporter genes encoding green fluorescent protein or chloramphenicol acetyl transferase.

Materials and Methods. NT-polyplex was injected into the substantia nigra. Double immunofluorescence labeling was used to reveal the cell type involved in the propidium iodide-labeled polyplex internalization and reporter gene expression.

Results. Polyplex internalization was observed within dopamine neurons but not within glial cells, and was pre-

vented by both hypertonic sucrose solution and SR-48692, a selective nonpeptide antagonist of NT receptors. Reporter gene expression was observed in dopamine neurons from $48 \mathrm{hr}$ up to 15 days after NT-polyplex injection, and was prevented by SR-48692. However, no expression was seen when the NT-polyplex was injected into the ansiform lobule of the cerebellum, which contains low- but not high-affinity NT receptors. Neither internalization nor expression was observed in cultured glial cells, despite the NT-polyplex binding to those cells that was prevented by levocabastine, a low-affinity NT receptor antagonist. Conclusions. These results suggest that high-affinity NT receptors mediate the uptake of NT-polyplex with the subsequent reporter gene expression in vivo. NT polyfection may be used to transfer genes of physiologic interest to nigrostriatal dopamine neurons, and to produce transgenic animal models of dopamine-related diseases.
\end{abstract}

\section{Introduction}

Some gene transfer systems have been successfully used in the central nervous system (CNS), yet some limitations such as lack of specificity and potential risks remain to be improved $(1,2)$. The receptormediated gene transfer system has been proposed as a specific and safe method for in vivo gene transfer (3). It relies on the formation of a conjugate by crosslinking poly-L-lysine with a ligand for which target cells have specific surface receptors that undergo endocytosis. A plasmid DNA (polyanion) is electrostatically bound to the poly-L-lysine (polycation) residue of the conjugate $(3,4)$ to form a complex,

Address correspondence and reprint request to: Daniel Martinez-Fong, MD, PhD, Departamento de Fisiología, Biofísica y Neurociencias, Centro de Investigación y de Estudios Avanzados del Instituto Politécnico Nacional, Apartado Postal 14-740, 07000 México D.F., México. Telephone: +525-747-7000; fax: +525-747-7105; E-mail: dmartine@fisio.cinvestav.mx known as a polyplex (5). When the ligand of the polyplex recognizes the appropriate cell-surface receptor, the polyplex is internalized via receptormediated endocytosis, cotransporting the foreign DNA $(3,4)$. Receptor-mediated gene delivery systems have been successfully used in vivo to transfer reporter genes $(3,6)$, antisense oligonucleotides (7), and genes of physiologic (8) and therapeutic (9) interest. However, the feasibility of receptormediated gene transfer has not been explored in the CNS yet.

Neurotensin (NT) is a suitable targeting molecule for gene delivery to CNS neurons, because it is rapidly internalized via its high-affinity receptor $(10,11)$. Once NT binds to the receptors, the ligandreceptor complex is endocytosed, being later localized unaltered near the cell nucleus (12). Taking advantage of the internalization properties of NT, we have recently synthesized a novel nonviral gene vector by cross-linking NT with poly-L-lysine (13), 
which was able to bind DNA (NT-polyplex) and to transfer plasmid DNA to cells in vitro bearing high affinity NT receptor (14). In the brain, mesostriatal and mesolimbic dopamine neurons have substantial density of high-affinity NT receptors localized in their soma and axonal terminals $(10,12,15)$. Thus, dopamine neurons of substantia nigra compacta represent a target for gene transfer via NT-polyplex. To test this possibility, we injected NT-polyplex into the substantia nigra. The receptor-mediated gene transfer of the NT-polyplex was confirmed by the blockade of the uptake by SR-48692, a potent and selective nonpeptide NT receptor antagonist (16). The gene expression was confirmed using reporter genes encoding chloramphenicol acetyl transferase (CAT) and green fluorescent protein encompassed in pSV2cat and pGreen Lantern 1, respectively.

\section{Materials and Methods}

\section{NT-Polyplex Formation}

NT was cross-linked with poly-L-lysine by means of N-succinimidyl-6-[3'-(2-pyridyldithio) propionamido]hexanoate (LC-SPDP) as described previously (13). Both the NT-SPDP-poly-L-lysine conjugate and the plasmid DNA (pSV2cat or pGreen Lantern-1) were dissolved in serum-free Dulbecco's Modified Eagle medium. NT-polyplex was formed at optimal molar ratio (DNA:conjugate) by slowly adding $0.12 \mathrm{ml}$ NT-SPDP-poly-L-lysine conjugate to $0.28 \mathrm{ml}$ plasmid DNA solution $(6 \mathrm{nM}$, final concentration) as described previously (13). The stability of the NT-polyplex was monitored by gel electrophoresis $(0.8 \%$ agarose, $80 \mathrm{~V}$, and $2 \mathrm{hr})(13)$.

\section{Animals}

Experiments were conducted on male Wistar rats (weighing 230-250 g at the onset of experiment) bred in our facilities. Animals were maintained under constant room temperature $\left(23^{\circ} \mathrm{C}\right)$ and light/ dark cycle (12:12 hr light/dark); with food and water ad libitum. All procedures were in accordance with the "Guide for the Care for and Use of Laboratory Animals" of the Mexican Council for Animal Care as approved by the CINVESTAV Animal Care Committee. All efforts were made to minimize animal suffering, reduce the number of animals used, and utilize alternatives to in vivo techniques.

\section{Surgical Procedures}

Each rat was anesthetized by an intraperitoneal injection of chloral hydrate $(350 \mathrm{mg} / \mathrm{kg})$ and placed in a stereotaxic instrument (David Kopf) with the incisor bar $3.3 \mathrm{~mm}$ below the interaural line. Kelatorphan $(50 \mathrm{mM})$, an in vivo endopeptidase inhibitor, was used to protect the NT moiety of polyplex against the enzymatic cleavage (17). After cranial trepanation, $2 \mu$ I NT-polyplex (6 $\mathrm{nM}$ with respect to DNA) containing kelatorphan were microinjected into the dorsal border of substantia nigra compacta at a rate of $0.1 \mu 1 / \mathrm{min}$. The coordinates were AP -4.9 from bregma; $\mathrm{L}+2.0$ from midline, VD -6.0 from the cortex surface (18). In addition, a local administration of $2 \mu \mathrm{l}$ of $50-\mathrm{mM}$ kelatorphan preceded the NT-polyplex administration. To visualize the NTpolyplex internalization, propidium iodide $(10 \mu \mathrm{M})$ was added to the NT-polyplex solution to label the plasmid DNA (pSV2cat or pGreen Lantern-1). To test the involvement of high-affinity NT receptors in the uptake of the polyplex, NT-polyplex-pSV2cat was microinjected into the molecular layer of the ansiform lobule of the cerebellum, which has low- but not high-affinity NT receptors $(19,20)$. The coordinates were AP -9.8 from bregma; $L+5.2$ from midline, VD -3.5 from the cortex surface (21). Kelatorphan and NT-polyplex administration in the ansiform lobule was similar to that of the substantia nigra compacta. Negative controls were rats injected with $2 \mu 1$ of 6-nM uncomplexed DNA into the substantia nigra compacta. To block the receptormediated endocytosis of NT-polyplex, $2 \mu \mathrm{l}$ of either $0.45 \mathrm{M}$ sucrose or $1 \mu \mathrm{M}$ SR-48692 containing kelatorphan was injected 10 min before and concurrently with the NT-polyplex. A stock solution of $10^{-2}$ M SR-48692 in dimethylsulfoxide was subsequently diluted with phosphate-buffered solu-tion (PBS) to yield a final concentration of $10^{-6} \mathrm{M}$, following the manufacturer's specification. After surgery, all animals were injected with benzathine penicillin $(300,000 \mathrm{UI} / \mathrm{kg}$, im) to prevent infection.

\section{Immunofluorescence}

Internalization was assessed $4 \mathrm{hr}$ after the injection of the NT-polyplex. Gene expression was verified from $48 \mathrm{hr}$ up to 90 days after polyfection. For immunofluorescence observations, rats were deeply anesthetized with chloral hydrate and perfused through the ascending aorta with $100 \mathrm{ml} \mathrm{Ca}^{2+}$ - and $\mathrm{Mg}^{2+}$-free PBS, pH 7.4, followed by $150 \mathrm{ml}$ of $4 \%$ paraformaldehyde in PBS. The brain was then removed and maintained in the fixative for $48 \mathrm{hr}$ at $4^{\circ} \mathrm{C}$. After overnight incubation in PBS containing $10 \%$ sucrose at $4^{\circ} \mathrm{C}$, the brain was frozen and sectioned in $30-\mu \mathrm{m}$ slices on the saggital plane using a Leitz cryostat. Slices were individually collected in a 24-well plates containing PBS, and used for fluorescent immunolabeling of dopamine neurons, astroglial cells, and the CAT gene product. Slices were incubated with $10 \%$ IgG-free bovine serum albumin (BSA) in PBS-Triton-X-100 $(0.2 \%)$ for $20 \mathrm{~min}$ at room temperature. The primary antibodies were mouse anti-tyrosine hydroxylase (TH) monoclonal antibody (1:20 dilution; Boehringer Mannheim, Indianapolis, IN, USA), rabbit anti-glial fibrilary acidic protein (GFAP) polyclonal antibody (1:400 dilution; Dako A/S, Carpinteria, CA, USA), and rabbit anti-CAT polyclonal antibody (1:50 dilution; 5 Prime $\rightarrow 3$ Prime). The secondary antibodies were fluorescein (FITC)- or rhodamine (Rho)-goat antimouse IgG (1:100 dilution; Pierce, Rockford, IL, 
USA), and FITC- (Vector Laboratories, Burlingame, CA, USA) or Rho-(Pierce) goat anti-rabbit IgG (1:60 dilution). Slices were mounted on glass slides using vectashield (Vector Laboratories) and then scanned in a confocal imaging system equipped with a kryptonargon laser beam (Bio-Rad MRC-600, Watford, UK). The fluorescence was detected with either $40 \times$ or $60 \times$ oil-immersion objectives at excitation/emission wavelengths of $488 / 522 \mathrm{~nm}$ (green channel) and $568 / 585 \mathrm{~nm}$ (red channel). Ten to twenty consecutive $1-\mu \mathrm{m}$ optical sections were obtained in the z-series. The resulting images were projected in a bidimensional plane and overlapped on the monitor using green for FITC and the green fluorescent protein, and red for propidium iodide and Rho. Negative controls were obtained by omitting the primary antibody and replacing it by an irrelevant antibody of the same IgG subclass.

\section{Chloramphenicol Acetyl Transferase Assay}

Rats were deeply anesthetized with chloral hydrate and decapitated. The brain was rapidly removed, immersed in ice-cold PBS, and mounted in a vibratome (Oxford) to obtain 200- $\mu$ m slices from the mesencephalon and the cerebellum. Samples from the pars compacta of the substantia nigra, a contiguous mesencephalic region above nigra, and the molecular layer of the ansiform lobule of the cerebellum were dissected out on a cold stage of a stereoscopic microscope and collected in separate $0.5-\mathrm{ml}$ tubes that were maintained in liquid $\mathrm{N}_{2}$ until use. Slices from six rats were pooled and homogenized after the addition of $0.5 \mathrm{ml}$ Tris-EDTA-NaCl $(0.04 \mathrm{M}$ Tris-HCl, $1 \mathrm{mM}$ EDTA $0.15 \mathrm{M} \mathrm{NaCl}, \mathrm{pH}$ 7.4). Homogenates were centrifuged at $14,000 \mathrm{rpm}$ in a Sorval MRC-14 microcentrifuge (Dupont, Boston, MA, USA) at $4^{\circ} \mathrm{C}$ for $5 \mathrm{~min}$. Supernatants with similar protein concentration $(2 \mu \mathrm{g} / \mu \mathrm{l})$ were incubated with $\left[{ }^{14} \mathrm{C}\right]$-chloramphenicol and acetyl-CoA $(4 \mathrm{mM})$ according to the method described previously (22). $\left[{ }^{14} \mathrm{C}\right]$-Chloramphenicol and acetylated $\left[{ }^{14} \mathrm{C}\right]-$ chloramphenicol were separated by thin-layer chromatography on silica plates and analyzed by a computerized autoradiography system (Instant Imager, Packard). Positive controls of the CAT assay were lysates from N1E-115 cells transfected with pSV2cat using the $\mathrm{DNA}^{-\mathrm{CaPO}_{4}}$ co-precipitation technique (23). Protein content was measured with the micro BCA reagent kit as described by the manufacturer (Pierce).

\section{Primary Astrocyte-Enriched Cultures From the Substantia Nigra}

Astrocyte-enriched cultures were obtained from neonate rat brains as described elsewhere (24). Briefly, the substantia nigra was dissected and incubated in a trypsin-EDTA solution $(0.1 \%$ and 5.6 $\mathrm{mM}$, respectively) for $10 \mathrm{~min}$. After the incubation, cells were mechanically dispersed and filtered through a $48-\mu \mathrm{m}$ nylon mesh and seeded $\left(2.4 \times 10^{6}\right.$ cells/ml) in 4-well plates containing Dulbecco's Modified Eagle Medium supplemented with $10 \%$ heat-inactivated fetal cow serum, $2 \mathrm{mM}$ L-glutamine, a penicillin-streptomycin mixture $(10,000 \mathrm{U} / \mathrm{ml}$ each) and amphotericin B $(25 \mu \mathrm{g} / \mathrm{ml})$. Cultures were kept at $37^{\circ} \mathrm{C}$ under a $5 \% \mathrm{CO}_{2}$ in $\mathrm{O}_{2}$ atmosphere. Culture media were replaced $24 \mathrm{hr}$ later and every 3 days thereafter.

Internalization and expression assays were performed using NT-polyplex-pGreen Lantern-1 formed at 1:35 molar ratio (6 nM cDNA : $210 \mathrm{nM}$ NT-vector) as described previously (13). The DNA of NT-polyplex was labeled with propidium iodide $(10 \mu \mathrm{M})$ in serum-free culture medium. Glial cells seeded in chamber slides at $\mathbf{8 0 \%}$ confluence were incubated with the propidium iodide-labeled NT-polyplex in the presence or absence of levocabastine $(1 \mu \mathrm{M})$. After 30-min incubation, the culture medium was removed and cells were washed three times with PBS, and then fixed with $4 \%$ paraformaldehyde in PBS at room temperature. To assay the expression, glial cells, cultured at approximately $50 \%$ confluence, were incubated with the NT-polyplex formed at optimal molar ratio in serum-free medium. After a 4-hr incubation, the medium was supplemented with fetal bovine serum to yield a $10 \%$ concentration. After $12 \mathrm{hr}$, the medium was replaced with fresh medium. After 48-hr incubation, cells were washed thrice with PBS and fixed with $4 \%$ paraformaldehyde in PBS. After fixation, cells were processed for indirect immunofluorescence using a rabbit anti-cow GFAP polyclonal antibody (1:400 dilution), which was revealed by the goat anti-rabbit IgG FITC in internalization assays or Rho conjugated (1:60 dilution) in expression assays. The fluorescence was detected with confocal microscopy at excitation/emission wavelengths of $488 / 522 \mathrm{~nm}$ (green channel) for FITC and green fluorescent protein, and at 568/585 $\mathrm{nm}$ (red channel) for propidium iodide and Rho.

\section{Assessment of Neuronal Expression}

Expression efficiency was obtained by counting the number of cells expressing the CAT product of pSV2cat in a total $1500 \mathrm{TH}$-positive cells, counted in 20 brain slices ( $n=8$ rats). For cell counting, four fields per slice using a $40 \times$ objective were examined. Values are expressed as the mean \pm standard deviation.

\section{Results}

\section{NT-Polyplex Internalization}

The uptake of NT-polyplex by dopamine neurons, revealed by anti-TH FITC-immunostaining, is shown in Figure 1. After $4 \mathrm{hr}$ of intranigral microinjection of propidium iodide-labeled NT-polyplex, red fluorescent marks were seen in FITC-immunolabeled dopamine neurons (Fig. 1A). Hypertonic sucrose solution, a condition that blocks endocytic vesicle formation (25), prevented the internalization of 

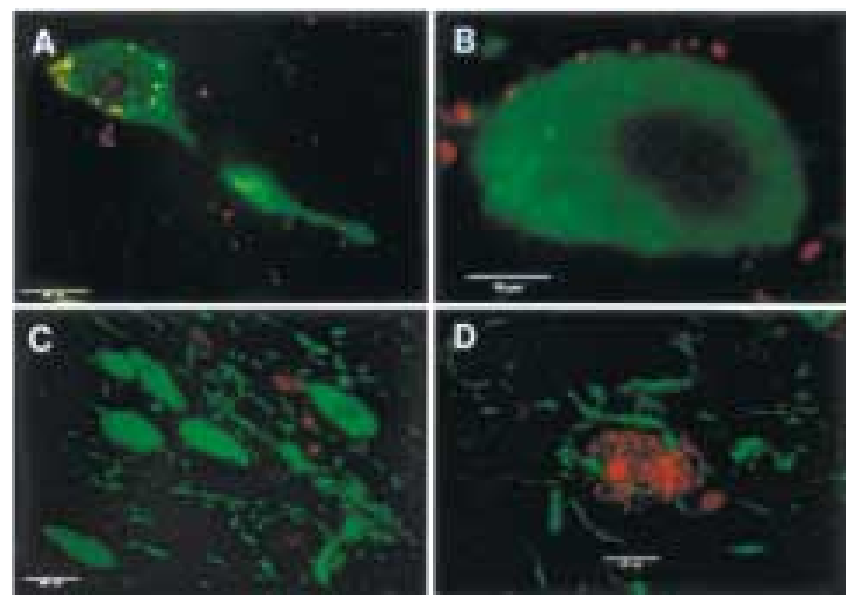

Fig. 1. Uptake of propidium iodide-labeled NT-polyplex by dopamine neurons of the substantia nigra. (A, B, and $\mathrm{C}$ ) Merged images of FITC-immunolabeled dopamine neurons (green) and propidium iodide-labeled NT-polyplex (red). (D) Merged image of FITC-immunolabeled glial cells (green) and propidium iodide-labeled NT-polyplex. (A) is $1-\mu \mathrm{m}$ optical section that shows the uptake of propidium iodide-labeled NT-polyplex by dopamine neurons. (B) is $1-\mu \mathrm{m}$ optical section that shows the blockade of the neuronal uptake of propidium iodide-labeled NT-polyplex by $0.45 \mathrm{M}$ sucrose solution. (C) is a $\mathrm{z}$-series projection that shows the absence of propidium iodide-labeled NT-polyplex internalization in dopamine neurons in presence of $1 \mu \mathrm{M}$ SR-48692. (D) is a $\mathrm{z}$-series projection that shows the inability of glial cells to internalize propidium iodide-labeled NT-polyplex.

propidium iodide-labeled NT-polyplex. In this condition, the red fluorescent marks were present only on the surface of dopamine neurons (Fig. 1B). The potent and selective nonpeptide NT receptor antagonist SR-48692 also blocked the internalization of the complex, because neither extracellular nor intracellular red fluorescent marks were seen in dopamine neurons (Fig. 1C). On the other hand, propidium iodide-labeled NT-polyplex was not seen in FITC-immunolabeled astrocytes, although it was localized in the same field within neuronal cells (Fig. 1D).

\section{NT-Polyplex-Mediated Gene Expression}

The expression of the green fluorescent protein did not colocalize with Rho-GFAP positive cells (Fig. 2A), which indicates a selective neuronal expression of the transgene. In line with this, CAT expression revealed by Rho-immunolabeling colocalized with FITC-immunolabeled dopamine neurons (Fig. 2B). The fraction of dopamine cells expressing reporter gene products was $5 \pm 4 \%(n=4$ independent experiments).

CAT expression was also confirmed measuring its enzymatic activity in homogenates of brain structures where NT-polyplex had been previously microinjected. CAT activity was detected in homogenates of nigra compacta, indicating the expression of the CAT gene (Fig. 3, lane B). Again, the blockade of the activation of NT receptors with SR-48692 prevented the
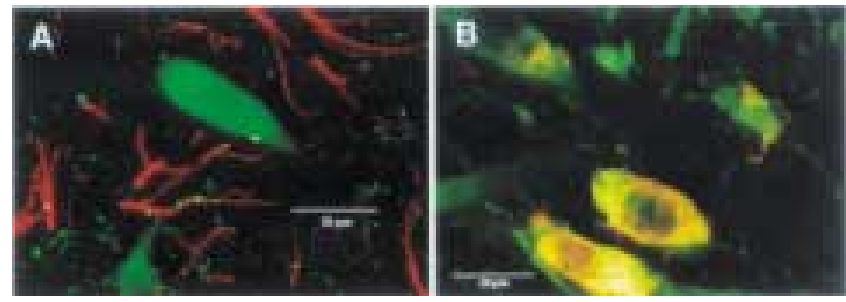

Fig. 2. Merged images showing expression of the genes encoding green fluorescent protein and chloramphenicol acetyl transferase in dopamine neurons. (A) Failure of Rhoimmunolabeled glial cells to express NT-polyfected green fluorescent protein. (B) Double immunolabeling with Rho-anti CAT and FITC-anti TH. The colocalization of NT-polyplex-mediated CAT expression (red) and FITC-TH-immunopositive dopamine neurons (green) is seen as a yellow pseudocolor. The panels are projections of respective z-series of horizontal sections.

expression of the transgene, as shown by the lack of enzymatic activity in homogenates of the substantia nigra compacta, where NT-polyplex was coadministered with SR-48692 (Fig. 3, lane C). Homogenates from tissues microdissected from a region contiguous to substantia nigra compacta (Fig. 3, lane D) or from the molecular layer of the ansiform lobule of the cerebellum (Fig. 3, lane E), although exposed to NTpolyplex-pSV2cat, did not show any CAT activity. CAT gene expression in lysates from N1E-115 cells

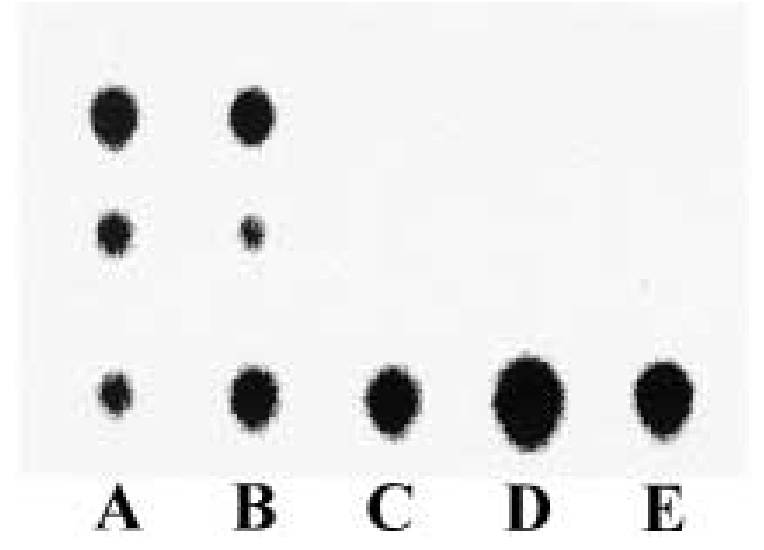

Fig. 3. High-affinity NT receptor involvement in NT-polyplex-mediated expression of the gene encoding chloramphenicol acetyl transferase. NT-polyplex-pSV2cat was microinjected into the pars compacta of the substantia nigra and into the molecular layer of the ansiform lobule of the cerebellum, where high-affinity NT receptors are absent. The figure is a representative autoradiography from three independent experiments showing a thin layer chromatography of $\left[{ }^{14} \mathrm{C}\right]$-chloramphenicol enzymatic acetylation. CAT gene expression in lysates from N1E-115 cells transfected with pSV2cat by the DNA-CaPO 4 co-precipitation technique was used as a positive control of the CAT assay (lane A). CAT activity in supernatants from homogenates of the entire pars compacta of the substantia nigra in the absence (lane B) or presence of SR-48692 (lane C). Neither homogenates from tissue over the polyfected substantia nigra pars compacta (lane D) nor those from the polyfected molecular layer of the ansiform lobule of the cerebellum (lane E) had detectable CAT activity. 
transfected with pSV2cat by the DNA-CaPO ${ }_{4}$ coprecipitation technique (23) was used as a positive control of the CAT assay (Fig. 3, lane A).

To evaluate the temporal course of the transgene expression, slices from the substantia nigra were obtained at 2, 15, 30 and 90 days after pGreen Lantern 1 polyfection. The green fluorescent protein was clearly detected from 2 days $(n=5)$ up to 15 days $(n=4)$ after polyfection. Only fluorescent vestiges were observed at 30 days after polyfection $(n=4)$, and no fluorescence was detected at 90 days after polyfection $(n=4)$.

\section{Internalization and Expression in Glial Cells From Substantia Nigra}

To confirm the in vivo failure of astrocytes to internalize the NT-polyplex and to express the reporter genes, internalization and expression assays were carried out in primary cultures of glial cells of substantia nigra. Anti-GFAP FITC-immunolabeled glial cells (Fig. 4A) incubated with propidium iodide labeled NT-polyplex showed red fluorescent marks only on their cellular surface (Fig. 4B). However, no fluorescence of propidium iodide-labeled NT-polyplex was detected (Fig. $4 \mathrm{D}$ ) when the glial cells (Fig. 4C) were incubated with $1 \mu \mathrm{M}$ levocabastine, a competitive antagonist of the low affinity NT receptor $(26,27)$. These results demonstrate
Ex/Em 488/522 am
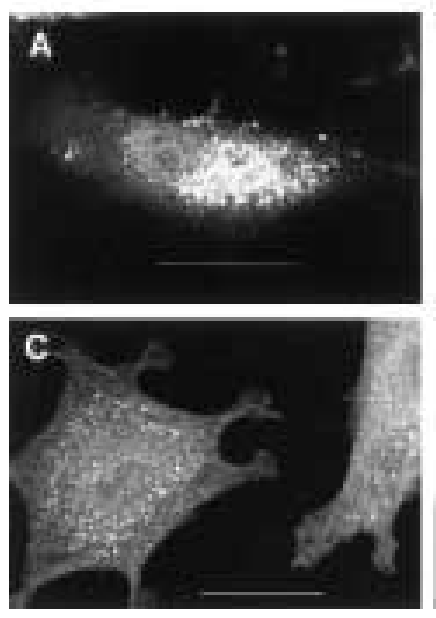

Ex/Em 568/585 nm
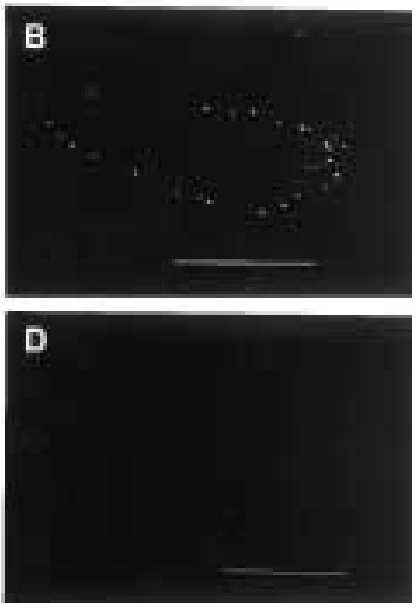

Fig. 4. Failure of low-affinity NT receptors of cultured astroglial cells to uptake the propidium iodide-labeled NT-polyplex. (A) and (C) are microphotographs obtained in the green channel of the confocal microscope from cultured glial cells FITC-immunolabeled for glial fibrilary acidic protein. (B) and (D) are microphotographs obtained in the red channel of the confocal microscope showing the fluorescence of propidium iodide-labeled DNA of the NT-polyplex. Microphotographs of the left column (A and $C$ ) and their respective counterparts of the right column (B and D) were obtained from the same fields. (A) and (B) are $1-\mu \mathrm{m}$ horizontal sections showing NT-polyplex binding to the cellular surface, but not internalization into the glial cell. (C) and (D) are projections of respective z-series of horizontal sections showing the blockade by levocabastine of NT-polyplex binding. that under the present conditions, low-affinity NT receptors are unable to internalize the NT-polyplex, although apparently they bound it. In agreement with the internalization results, primary cultures of astrocytes were not able to express the green fluorescent protein delivered by the NT-polyplex (data not shown).

\section{Discussion}

The present results show the feasibility of gene transfer into central dopamine cells using NT-polyplex to internalize the gene. Of the three NT receptors that have been characterized in human and adult rodent brain $(11,27,28)$, high-affinity NT receptors may account for the internalization of NT-polyplex because these receptors are present in dopamine neurons and are able to internalize NT $(10,12)$. After its internalization, NT has been shown to be unaltered near the cell nucleus (12), suggesting that it is able to escape from endosomes before their fusion with lysosomes, the main limiting barrier to receptor-mediated gene transfer systems (29). The NT moiety of polyplex may have provided the escape route from endosomes to plasmid DNA during its transport, thus allowing the transgene expression. The process by which the transgene is incorporated to the cell nucleus remains to be studied. Both the NT-polyplex internalization and reporter gene expression in dopamine neurons were prevented by $1 \mu \mathrm{M}$ SR48692. This concentration would saturate not only high- (16), but also low-affinity NT receptors $(30,31)$, which raises the possibility of the participation of the latter receptors in NT polyfection. Low-affinity NT receptor is expressed by both neurons (32) and glial cells (11) in adult rat brain. However, in the conditions of the present experiments, that receptor appears not to have been involved in the internalization of the NT-polyplex, because neither internalization nor expression were observed in cultured GFAP-positive cells. Furthermore, the failure of NTpolyplex to produce CAT expression in the molecular layer of the ansiform lobule of the cerebellum, where high-affinity NT receptors are absent and lowaffinity receptors present $(19,20)$, gives further support to the participation of high-affinity NT receptors in the uptake of the NT-polyplex. Moreover, we have recently demonstrated the involvement of highaffinity neurotensin receptors in NT-polyfection in vitro (14).

The present results have shown that we were able to transfer genes into dopamine neurons via NTpolyplex, although the efficiency of transfection was very low in comparison to lentiviral vector transfection (2). The low efficiency of transfection might have been due to the gradual acidification of the endocytic vesicle (33), which might have prevented the escape of the NT-polyplex from endosomes before the critical point of acidification. The use of strategies such as addition of fusogenic peptides (34) to the 
NT-vector that can rescue the NT-polyplex from endosomes earlier could result in a consistently higher expression of the gene of interest.

The NT-polyfection resulted in transient expression of reporter genes; it lasted only 15 days. It will be necessary to look for means of substantially prolonging the expression. It has been long considered that the use of tissue specific promoters in receptormediated gene transfer systems can improve transgene expression in vitro (4) and produce long-term transgene expression in vivo (3). Accordingly, the use of the promoter of the gene encoding dopamine transporter (35) might improve the in vivo expression of genes transfected by NT-polyplex in dopamine neurons.

In summary, NT-polyfection is a method that, once the problems of the low efficiency and transient expression have been solved, could be used to transfer genes of therapeutic or experimental utility to central dopamine neurons. Recent data have shown that both BDNF and GDNF promote the maintenance and the survival of nigral dopamine neurons (36-38) leading to increased interest in using them as therapeutics modalities for Parkinson disease. NT-polyplex would be useful in defining the role of these neurotrophic factors in the response of dopamine nigral neurons to injury and in exploiting their therapeutic potential in Parkinson's disease. Because dopamine $\mathrm{D}_{2}$ receptor up-regulation seems to be involved in schizophrenia (39), NT-polyplex may be used to transfer antisense oligonucleotides that would control overexpression of the gene encoding $\mathrm{D}_{2}$ receptors in mesolimbic dopamine neurons, because they also express high-affinity NT receptors (20).

\section{Acknowledgments}

We are grateful to Dr. Danielle Gully (Sanofi Recherche, France) for the generous gift of SR48692, Dr. Marcel Janssen (Janssen Research Foundation, Belgium) for the generous gift of levocabastine hydrochloride, and Dr. Bernard P. Roques (Univeristé Rene Descartes, France) for the generous gift of kelatorphan. The excellent technical assistance of Ignacio Araoz, Alejandro Nuñez, and José Luna is gratefully acknowledged. Ikuri Alvarez was recipient of a scholarship from CONACYT. Ivan Navarro-Quiroga is a student of the Doctoral Program in Biomedical Science of the Autonomous National University of Mexico. The study was supported by the grants 3049PM and 28260M from CONACYT of Mexico. The authors thank Dr. LouisEric Trudeau for his critical revision of the manuscript and suggestions.

\section{References}

1. Garcia-Valenzuela E, Rayanade R, Perales JC, Davidson CA, Hanson RW, Sharma SC. (1997) Axon-mediated gene transfer of retinal ganglion cells in vivo. J. Neurobiol. 32: 111-122.
2. Naldini L, Blömer U, Gallay P, et al. (1996) In vivo gene delivery and stable transduction of nondividing cells by a lentiviral vector. Science 272: 263-267.

3. Wu CH, Wilson JM, Wu GY. (1989) Targeting genes: delivery and persistent expression of a foreign gene driven by mammalian regulatory elements in vivo. J. Biol. Chem. 264: 16985-16987.

4. Martinez-Fong D, Mullersman JE, Purchio AF, ArmendarizBorunda J, Martinez-Hernandez A. (1994) Nonenzymatic glycosylation of poly-L-lysine: a new tool for targeted gene delivery. Hepatology 20: 1602-1608.

5. Felgner PL, Barenholz Y, Behr JP, et al. (1997) Nomenclature for synthetic gene delivery systems. Hum. Gene Ther. 8: 511-512.

6. Ziady AG, Ferkol T, Dawson DV, Perlmutter DH, Davis PB. (1999) Chain length of the polylysine in receptor-targeted gene transfer complexes affects duration of reporter gene expression both in vitro and in vivo. J. Biol. Chem. 274: 4908-4916.

7. Bunnell BA, Askari FK, Wilson, JM. (1992) Targeted delivery of antisense oligonucleotides by molecular conjugates. Somat. Cell Mol. Gen. 18: 559-569.

8. Kollen WJW, Mulberg AE, Wei XF, et al. (1999) High-efficiency transfer of cystic-fibrosis transmembrane conductance regulator cDNA into cystic-fibrosis airway cells in culture using lactosylated polylysine as a vector. Hum. Gene Ther. 10: 615-622.

9. Wu GY, Wilson JM, Shalaby F, Grossman M, Shafritz DA, Wu CH. (1991) Receptor-mediated gene delivery in vivo. Partial correction of genetic analbuminemia in Nagase rats. J. Biol. Chem. 266: 14338-14342.

10. Faure MN, Alonso A, Nouel D, Gaudriault G, Dennis M, Vincent JP, Beaudet A. (1995) Somatodendritic internalization and perinuclear targeting of neurotensin in the mammalian brain. J. Neurosci. 15: 4140-4147.

11. Nouel D, Faure MP, St Pierre JA, Alonso R, Quirion R, Beaudet A. (1997) Differential binding profile and internalization process of neurotensin via neuronal and glial receptors. J. Neurosci. 17: 1795-1803.

12. Castel MN, Beaudet A, Laduron PM. (1994) Retrograde axonal transport of neurotensin in rat nigrostriatal dopamine neurons, modulation during ageing and possible physiological role. Biochem. Pharmacol. 47: 53-62.

13. Martinez-Fong D, Navarro-Quiroga I. (2000) Synthesis of a non-viral vector for targeted gene delivery to cells expressing the high affinity neurotensin receptor. Brain Res. Protocols 6: 13-24.

14. Martinez-Fong D, Navarro-Quiroga I, Ochoa I, Alvarez-Maya I, Meraz MA, Luna J, Arias-Montaño JA. (1999) Neurotensin-SPDP-poly-L-lysine conjugate: a nonviral vector for targeted gene delivery to neural cells. Brain Res. Mol. Brain Res. 69: 249-262.

15. Kitabgi P. (1989) Neurotensin modulates dopamine neurotransmission at several levels along brain dopamine pathways. Neurochem. Int. 14: 111-119.

16. Gully D, Canton M, Boigegrain R, et al. (1993) Biochemical and pharmacological profile of a potent and selective nonpeptide antagonist of the neurotensin receptor. Proc. Natl. Acad. Sci. USA 90: 65-69.

17. Waksman G, Bouboutou R, Devin J, et al. (1985) In vitro and in vivo effects of kelatorphan on enkephalin metabolism in rodent brain. Eur. J. Pharmacol. 117: 233-243.

18. Góngora-Alfaro JL, Hernández-López S, Martinez-Fong D, Aceves J. (1996) Circling behavior elicited by cholinergic neurotransmission in the substantia nigra pars compacta: involvement of nicotinic and muscarinic receptors. Neuroscience 71: 729-734.

19. Lepee-Lorgeoux I, Betancur C, Rostene W, Pelaprat D. (1999) Differential ontogenetic patterns of levocabastine-sensitive neurotensin NT2 receptors and of NT1 receptors in the rat brain revealed by in situ hybridization. Brain Res. Dev. Brain Res. 113: 115-131.

20. Mendez M, Souaze F, Nagano M, Kelly PA, Rostene W, Forgez P. (1997) High affinity neurotensin receptor mRNA distribution 
in rat brain and peripheral tissues. Analysis by quantitative RT-PCR. J. Mol. Neurosci. 9: 93-102.

21. Paxinos G, Watson C. (1986) The rat brain in stereotaxic coordinates. (2nd edition). New York, Academic Press.

22. Gorman CM, Moffat LF, Howard BH. (1982) Recombinant genomes which express chloramphenicol acetyltransferase in mammalian cells. Mol. Cell. Biol. 2: 1044-1051.

23. Graham FL, van der Eb AJ. (1973) A new technique for the assay of infectivity of human adenovirus 5 DNA. Virology 52: 456-467.

24. Chao CC, Hu S, Sheng WS, Bu D, Bukrinsky MI, Peterson PK. (1996) Cytokine-stimulated astrocytes damage human neurons via a nitric oxide mechanism. Glia 16: 276-284.

25. Heuser JE, Anderson RG. (1989) Hypertonic media inhibit receptor-mediated endocytosis by blocking clathrin-coated pit formation. J. Cell. Biol. 108: 389-400.

26. Schotte A, Leysen JE, Laduron PM. (1986) Evidence for a displaceable non-specific $\left[{ }^{3} \mathrm{H}\right]$ neurotensin binding site in rat brain. Naunyn Schmiedebergs Arch. Pharmacol. 333: 400-405.

27. Kitabgi P, Rostene W, Dussaillant M, Schotte A, Laduron PM, Vincent JP. (1987) Two populations of neurotensin binding sites in murine brain: discrimination by the antihistamine levocabastine reveals markedly different radioautographic distribution. Eur. J. Pharmacol. 140: 285-293.

28. Mazella J, Zsurger N, Navarro V, et al. (1998) The 100-kDa neurotensin receptor is gp95/sortilin, a non-G-protein-coupled receptor. J. Biol. Chem. 273: 26273-26276.

29. Mislick KA, Baldeschwieler JD, Kayyem JF, Meade TJ. (1995) Transfection of folate-polylysine DNA complexes: evidence for lysosomal delivery. Bioconjug. Chem. 6: 512-515.

30. Mazella J, Botto J, Guillemare E, Coppola T, Sarret P, Vincent JP. (1996) Structure, functional expression, and cerebral localization of the levocabastine-sensitive neurotensin/neuromedin $\mathrm{N}$ receptor from mouse brain. J. Neurosci. 16: 5613-5620.
31. Betancur C, Canton M, Burgos A, Labeeuw B, Gully D, Rostene W, Pelaprat D. (1998) Characterization of binding sites of a new neurotensin receptor antagonist, [3H]SR 142948A, in the rat brain. Eur. J. Pharmacol. 343: 67-77.

32. Sarret P, Beaudet A, Vincent JP, Mazella J. (1998) Regional and cellular distribution of low affinity neurotensin receptor mRNA in adult and developing mouse brain. J. Com. Neurol. 394: 344-356.

33. Clague MJ. (1998) Molecular aspects of the endocytic pathway. Biochem. J. 336: 271-282.

34. Kichler A, Freulon I, Boutin V, Mayer R, Monsigny M, Midoux P. (1999) Glycofection in the presence of anionic fusogenic peptides: a study of the parameters affecting the peptide-mediated enhancement of the transfection efficiency. J. Gene. Med. 1: 134143.

35. Sacchetti P, Brownschidle LA, Granneman JG, Bannon MJ. (1999) Characterization of the 5 '-flanking region of the human dopamine transporter gene. Brain Res. Mol. Brain. Res. 74: 167-174.

36. Beck KD, Valverde J, Alexi T, et al. (1995) Mesencephalic dopamine neurons protected by GDNF from axotomy-induced degeneration in the adult brain. Nature 373: 339-341.

37. Klein RL, Lewis MH, Muzyczka N, Meyer EM. (1999) Prevention of 6-hydroxydopamine-induced rotational behavior by BDNF somatic gene transfer. Brain Res. 847: 314-320.

38. Mandel RJ, Snyder RO, Leff SE. (1999) Recombinant adenoassociated viral vector-mediated glial cell line-derived neurotrophic factor gene transfer protects nigral dopamine neurons after onset of progressive degeneration in a rat model of Parkinson's disease. Exp. Neurol. 160: 205-214.

39. Serretti A, Lilli R, Lorenzi C, Smeraldi E. (2000) Further evidence supporting the association between the dopamine receptor D2 Ser/Cys3 11 variant and disorganized symptomatology of schizophrenia. Schizophr. Res. 43: 161-162. 